человека в контексте эволюции культуры // Исторические, философские, политические и юридические науки, культурология и искусствоведение. Вопросы теории и практики. 2011. № 8, ч. 4. С. 27-29.

7. Соловьев В. С. Соч. : в 2 т. М., 1988. Т. ІІ. 822 с.

8. Визгин В. П., Пустарнаков В. Ф., Соловьев Э. Ю. Нигилизм // Новая философская энциклопедия : в 4 т. M., 2010. T. 3. C. 84-85.

\section{Philosophical Definition of the Overman}

\section{A. Belyaev \\ Lipetsk State Pedagogical University \\ 42, Lenins, Lipetsk, 398020, Russia \\ E-mail:dm.a.belyaev@gmail.com}

The article is devoted to complex philosophical definition of the concept of «overman» which is relevant to many contemporary philosophicalanthropological, axiological and cultural-philosophical researches. First of all, a comparative analysis of the concept of «overman» in his comparison with the German term «Übermensch» is carried out in this work. The idea of immediate connection between man and overman is substantiated where the last one is as a horizon of an anthropological ultimacy within a particular discourse. The local constants of human nature are emphasized and their model of reconstruction in the measurement of «over» is realized. In the concluding part of the article it's said that the basis for determining the term «overman» may be the principles of the «nomadic transgressive» and «anthropological inomernost» which allow us to speak of the overman as a non-constant anthropic unit which is associated with the subjective consensus state of "over».

Key words: overman, Übermensch, human, anthropological transgression, attribute of overman nomadichnost of human.

\section{References}

1. Belyaev D. A. Spetsifika lingvosemanticheskogo bytovaniya termina/ponyatiya «sverkhchelovek» v nemetskoy,

УДК 101.8

\section{ПРИНЦИПЫ КОНЦЕПТУАЛИЗАЦИИ И РИСКИ ФИЛОСОФСТВОВАНИЯ}

\author{
Беляев Евгений Иванович - \\ доктор философских наук, \\ профессор кафедры теоретической и социальной философии, \\ Саратовский государственный университет \\ E-mail: Belyaev214@mail.ru
}

Принципы концептуализация и риски философствования рассматриваются с точки зрения дисциплинарной специфики современной философии. Исследуются принципы научной концептуализации, такие как: ориентация, редукция, ясность, систематизация, экономия, эвристическая значимость. Показывается специфика концептуализация в философском контексте; раскрываются внутренние и внешние риски философствования и их начала. Другими словами, философия как философствование остается значимой своей рефлексивной и дискурсивной вовлеченностью в мир, специфическим инструментарием анализа и синтеза, russkoy i angliyskoy yazykovykh traditsiyakh (Specificity linguistically-semantically existence of the term/concept of «overman» in German, Russian and English language traditions). Fundamental'nie issledovaniya (Fundamental research), 2013, no. 4, pt. 2, p. 511-514.

2. Sineokaya Yu. V. Rubezh vekov: russkaya sudba Sverkhcheloveka Nitsshe (The turn of the century: the fate of the Russian Nietzsche's Overman). Fridrikh Nitsshe $i$ filosofiya $v$ Rossii: sbornik statey (Friedrich Nietzsche and Philosophy in Russia: collection of articles). St.-Petersburg, 1999, pp. 58-74.

3. Gofman T. V. Kontseptualizatsiya prostranstva v semantike predlogov: dis. ... kand. filol. nauk (The conceptualization of space in the semantics of prepositions: Diss. Ph.D). Moscow, 2005. 179 p.

4. Gurevich P. S. Fenomen deantropologizatsii cheloveka (The phenomenon of human anti-anthropologization). Voprosy filosofii (Voprosy Filosofii), 2009, no. 3, pp. 19-31.

5. Saykina G. K. Trudno byt'chelovekom... (Metafizicheskie marshruty cheloveka) (It's hard to be a human... Metaphysical human's routes). Kazan, 2012. 428 p.

6. Belyaev D. A. Invarianty bessmertiya i fenomen sverkhcheloveka v kontekste evolyutsii kultury (Immortality invariants and overman phenomenon in culture evolution context). Istoricheskie, filosofskie, politicheskie $i$ yuridicheskie nauki, kul'turologiya i iskusstvovedenie. Voprosy teorii i praktiki (Historical, philosophical, political and legal sciences, cultural studies and art history. Theory and practice), 2011, no. 8, pt. 4, pp. 27-29.

7. Solovev V. S. Sochineniya: $v 2 t$. (Works: in 2 vol.), Moscow, 1988, vol. II. 822 p.

8. Vizgin V. P., Pustarnakov V. F., Solovev E. Yu. Nigilizm (Nihilism). Novaya filosofskaya entsiklopediya: $v 4 t$. (New Encyclopedia of Philosophy: in 4 vol.), Moscow, 2010, vol. 3, pp. 84-85.

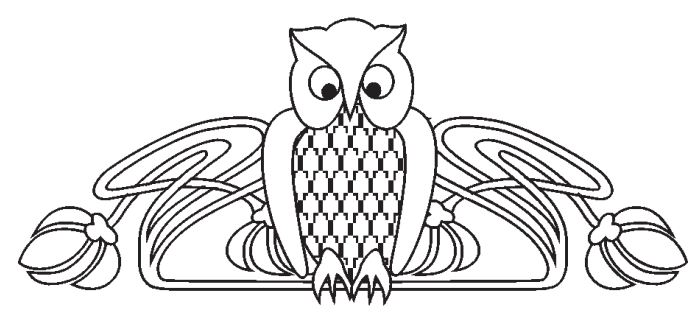

критическими и конструктивными устремлениями: в этом пункте скрываются начала рисков философствования.

Ключевые слова: принципы концептуализации, внешние и внутренние риски, начала рисков философствования.

Опыт философии риска показывает, что природа рискологии лежит не в фактах, ею открываемых, а в процессе концептуализации, посредством которого их обнаруживают. Концептуализация способствует развитию творческого 
отношения, и в этом заключается ее значение для науки вообще и рискологии в частности. Процесс концептуализации, в сущности, художественный: это «внутренний спор или диалог» $[1$, с. 25], а понимание теории включает осознание ее социально-исторических предпосылок.

Наука представляет собой систематическую попытку доказать осмысленность человеческого опыта. Она функционирует на абстрактном и эмпирическом уровнях. Возможно, что факты и эмпирические данные - продукт неосознанной концептуализации: «они не навязываются нам ощущениями, точно так же вообще не существует самоочевидных фактов» $[1$, с. 26]. Понятия представляют собой абстрактные умственные конструкции, являющиеся орудиями, инструментами понимания действительности, поэтому они имеют «измерение реальности» и «измерение идеальности». Многозначность и емкость понятия определяется его местом и функциями в разных смысловых системах. С помощью одних понятий организуются идеи, с помощью других - факты и наблюдения. Одни понятия служат для описания реальности, другие - для ее объяснения. «Последовательная научная система нуждается не только в понятийном инструментарии всех видов и уровней абстракции, но также в понятиях, способных объединить ее различные уровни» [1, с. 26].

В истории науки можно обнаружить два типа процессов концептуализации: спецификацию понятий, приводящую к большей ясности в понимании действительности, и их обобщение, дающее большую систематичность. Можно выделить несколько принципов научной концептуализации, в соответствии с которыми могут быть оценены ее результаты: 1) принцип ориентации, согласно которому понятия призваны направлять внимание исследователей лишь на отдельные стороны реальности, ибо мир слишком сложен, чтобы его понимали во всеобщности; 2) принцип редукции, в соответствии с которым ученый должен ясно отдавать себе отчет в том, от изучения каких аспектов, сторон действительности он отказывается в ходе концептуализации. Ввиду этого всякая концептуализация есть редукция информации; 3 ) принцип ясности: она достигается за счет операционализации понятия, хотя это и не единственный способ. Указывать границы применимости понятия необходимо также для того, чтобы не принимать гипотетическое за закономерное; 4) принцип систематизации, последняя необходима при наличии противоречивых данных и интерпретаций. Систематизация многопланова: так, путем операционального определения понятие соотносится с миром наблюдений: понятия соединяют частную теорию с общей или со смежными областями знания, наконец, с философией науки; 5) принцип экономии, который означает, что концептуализация есть способ упрощения мыслей и данных, и поэтому бессмысленно подменять сложность действительности сложностью понятий; 6) принцип эвристической значимости, в силу которого «внутренней целью научной концептуализации является стимулирование интеллектуальной деятельности и создание ощущения творческой свободы индивида» [2, с. 20]. Все вышеперечисленные принципы вторичны по отношению к этому последнему.

Принципиально важно отметить, что концептуализация есть комплексное понятие, достоинством которого является способность заменять более частные «формулирование», «обобщение», «абстрагирование» и «рефлексия» и тем самым способствовать сближению модернистской и постмодернистской методологий социального философствования. Ведь концептуализация в духе постмодерна означает «схватывание», идею, замысел, систему взглядов, понятий, тогда как контекст - завершенное в смысловом отношении целое, его частью является фон, на котором развивается процесс концептуализации. Понятие и контекст тесно связаны и взаимно дополняют друг друга «подобно ключу и замочной скважине»: как не всякий ключ может отворить любую дверь, так и не всякий концепт может «работать» в любом контексте. По аналогии с генотипом, средой и фенотипом можно сказать, что «генотип (концепт) развивается и раскрывается в определенных условиях среды (контекст)» [3, с. 56].

Сказанное позволяет понять специфику концептуализация в философском контексте: здесь она связана с так называемым «контекстуальнылм поворотом», как его именуют по аналогии с лингвистическим, онтологическим, практическим поворотами в интеллектуальной истории западной философии. В социальной философии анализ Дж. Остина «случая» и «контекста» высказываний или выражений получил благодаря Дж. Сирлю универсальное значение. В социологии и психологии работа Б. Бернштейна и Д. Брунера о «контекстуально зависимом» и «контекстуально независимом» обучении иллюстрирует эту же тенденцию. В литературной критике идея помещения поэмы «в контекст» и даже «в тотальный контекст» была обоснована критиком Ф. Бэтсоном и денонсирована Ф. Льюисом, который утверждал, что «социальный контекст» означает просто «личную жизнь индивидуума». В 1950-1960-х гг. социолингвисты Д. Хаймс и У. Уильям отметили, что одни и те же люди говорят по-разному в зависимости от контекста или ситуации. Даже в случае пра- 
ва, касающегося общих правил, было отмечено возникновение «восприимчивости к контексту». В социологии Э. Гидденс описал «локальное» как существенное для того, что он называет «контекстуальностью» социального взаимодействия или интеракции, тогда как феминисты, например Д. Хеарвэй, возродили и ревизовали понятие «ситуативного знания» К. Мангейма [4. с. 379].

Именно идея «критической профессии» помогла философии выстоять перед вызовами, спровоцированными развитием науки. Становится все более очевидным, что смысл понятия «философия» непрерывно изменяется в зависимости от её положения в системе наук, поэтому ложно полагать, что любая из современных концепций философии смогла бы раз и навсегда стать вечной и неизменной точкой отсчета развития. Не только понятие философии, но и само философствование связано с контекстами. Философская деятельность детерминирована не только движением вперёд работающих философов, но также эвристикой, которой они следуют, но она, однако, может и не быть эксплицитно выражена. Она детерминирована молчаливым знанием, принятым в их время, или внешними факторами относительно автономного мышления, такого, как дискуссия внутри дисциплины или рецепция предшествующих либо соперничающих концепций истолкования темы. В философии, как в других науках, именно профессиональная практика коррелирует собственную работу индивидуума с состоянием научно-исследовательской деятельности.

Философские дискуссии являются обсуждением фундаментальных и вечных вопросов, которые образуют проблемное поле онтологии, эпистемологии или метатеории. В отличие от них любая часть эмпиирического исследования привязана к конкретному месту и времени проведения, описания и обоснования. Методологи не могут подстраиваться под профессиональных философов. Напротив, их задача состоит в том, чтобы выработать практические философии социальной науки - методологии, которые обеспечивают конкретные руководства научно-исследовательской практики и критерии того, какое знание следует считать научным. Эти практические требования обязывают методологии быть последовательными, однако история методологических споров показывает обратное: концептуальное ядро методологии оказывается набором противоречивых дефиниций.

Факт существования разных школ философствования и разных научно-исследовательских технологий социальной науки подтверждает вероятность того, что существует семейство методологий, содержащее, как минимум, три практические философии рисков науки, которые являются результатом стихийной практики познания ученых. Они включают философию рисков естественных наук: это в XX в. - логический позитивизм, критический рационализм К. Поппера, исследовательские программы И. Лакатоса, спор между К. Куном и К. Поппером, аналитическая философия науки. К философской рискологии социальных наук можно отнести американский прагматизм, европейскую критическую теорию, точечные эпистемологии. Философская рискология гуманитарных наук (феноменология, герменевтика, структурализм и постструктурализм) использует формальный лингвистический и нарративный анализ, дискурсивный анализ, историю понятий, контентанализ, неформальные методы текстуальной экзегезы классических текстов в социальной теории для построения более широкой «философской истории риска», т.е. методы, присущие гуманитарным наукам.

Два из этих трех кластеров проявились в «битве за методологию» в форме критики позитивизма в социологии 1960-х гг., научных войнах науки 1990-х гг. и дебатах о «перестройке» в современной политической науке США. Третья (контекстуалистская) альтернатива была менее очевидной, и она редко обсуждалась как самостоятельная, однако опыт развития методологии рискологии показывает, что контекстуалистская позиичя является для нее самой важной. В этом случае философия рассматривается как орудие познания, целью которого является лингвистическое прояснение смыслов и референтов дискурса, облегчающих понимание и коммуникацию говорящих.

Ядерным компонентом современной философии является лингвистический, поскольку множество проблем, споров, как больших, так и незначительных, пронизывающих повседневную коммуникацию, являются результатом недопонимания и хаотизации языковой практики. Два человека входят в ожесточенное обсуждение и упорное препирательство, потому что каждый из них использует слова или предложения, значения и смыслы которых не ясны ни тому, ни другому. Каждый использует слово или предложение, значение или смысл которого отличаются контекстом употребления: иначе говоря, непонимание и хаотизация порождаются контекстуальной неопределенностью. Слова и выражения могут иметь различные значения в различных контекстах коммуникации: контекст есть локус определения, потому что слова или выражения используются сообразно пониманию их пользователем, поэтому, чтобы определить меру философичности темы диспута, необхо- 
димо предварительно выяснить, в каком смысле диспутант использует слова своего дискурса. Следовательно, главным философским вопросом в современном контексте будет: Какой конкретный смысл вы вкладываете в слова вашего высказывания? С этим связано использование аналитических и синтетических процедур критики и оценки дискуссии в главных областях философствования - метафизике (космологии и онтологии), аксиологии (этике и эстетике) и методологии (логике и эпистемологии).

Хотя философия утратила статус супернауки, она не лишилась ее релевантности при оценке этической ценности, эпистемологической значимости и онтологической целесообразности научных дискуссий. Другими словами, философия как философствование остается значимой благодаря своей рефлексивной и дискурсивной вовлеченности в мир, своему специфическому инструментарию анализа и синтеза и своим критическим и конструктивным устремлениям. В этом пункте скрываются начала рисков философствования.

Философствование сталкивается с опасностью догматизма, политического или религиозного. В условиях политического или религиозного насилия, где свобода выражения ограничена, риск утраты критического и дискурсивного философствования (проводимого и аналитически и синтетически) чрезвычайно высок, о чем свидетельствуют история палестино-израильского конфликта и идеологии тоталитаризма в СССР в период холодной войны. Важно отметить, что этот тип псевдофилософствования опасен внутренними рисками разрушения концептуального ядра самой дисциплины - Философии.

Известно, что Сократ, будучи великим патриотом, смотрел на свое философствование как на служение родине. Его жизнь была жизнью философа, образцом мужественности в столкновения с внешними рисками философствования в социальной среде засилья софистов, враждебных достижению истины, и превращал философию во внутренне рискованное состояние, таящее угрозу самоуничтожения. Смерть Сократа доказала полную гармонию его учения и действия.

Современная философия продолжает противостоять множеству внешних и внутренних рисков тогда и там, где и когда эти риски несут угрозу взвешенному критическому обсуждению конкретных спорных вопросов и проблем. Методологическая неустойчивость вызывается слишком большим количеством анализа, который почти полностью игнорирует синтез, и наоборот: таковы внешние и внутренние риски философии. Наконец, риск философствования состоит в том, что эта деятельность может быть дестабилизи- рующей и угрожать предвзятыми понятиями о мире, а дефицит широкого распространения критического мышления - быть угрозой существованию человечества [5].

\section{Список литературы}

1. George P. Conceptualisation - the central problem of the science. Warszawa,1973. № 9. Р. 23-33.

2. Концептуализация и контекстуализация в науката и образованието // Стратегии на образователната и научната политика. София, 2003. С. 12-30.

3. Meaning and context : quentin skinner and his critics / ed. J. Tully. Cambridge, 1988. P. 46-57.

4. Mjøset L. Can grounded theory solve the problems of its critics? // Sosiologisk Tidsskrift. 2005. Vol. 13, № 4. P. 360-380.

5. Ruel F. Pepa's the relevance of linguistic analytic philosophy in the postindustrial era. URL: http/www.facebook. $\mathrm{com} /$ notes/ruel-pepa/the-relevance-of-linguistic-analytic-philosophy-in-tre-postindustrial-era/1858468014508345\%5D (дата обращения: 25.01.2014).

\section{The Principles of Conceptualization and the Risks of Doing of Philosophy}

\section{E. I. Beliaev}

Saratov State University

83, Astrakhanskaya, Saratov, 410012, Russia

E-mail: Belyaev214@mail.ru

The practice of philosophy of risks shows that the nature of riskology lies in the process of conceptualization but not in the opened facts. The principles of scientific conceptualization are studied such as principles of orientation, reduction, clarity, systematisaton, economy, heuristic significance. Specific of conceptualization in philosophy are demonstrated. Internal and external risks are revealed, and their beginnings. In other words the philosophy as philosophizing is significant by his own reflective and discursive involving in the world, his specific methods of analysis and synthesis and his critical and constructive intentions. In this point implicitly are consisted the beginnings of the risks of all philosophizing.

Key words: principles of conceptualization, external and internal risks, beginnings of risks of philosophizing.

\section{References}

1. George P. Conceptualisation - the central problem of the science. Warszawa,1973, no. 9, pp. 23-33.

2. Konceptualizaciya i kontekstualizaciya v naukata $\mathrm{i}$ obrazovanieto. Strategii na obrazovatelnata i nauchnata politika. Sofiya, 2003, pp. 12-30.

3. Meaning and context: quentin skinner and his critics. Ed. J. Tully. Cambridge, 1988, pp. 46-57.

4. Mjøset L. Can grounded theory solve the problems of its critics? Sosiologisk Tidsskrift, 2005, vol. 13, no. 4, pp. 360-380.

5. Ruel F. Pepa's the relevance of linguistic analytic philosophy in the postindustrial era. Available at: http/ www.facebook.com/notes/ruel-pepa/the-relevance-oflinguistic-analytic-philosophy-in-tre-postindustrialera/1858468014508345\%5D (accessed 25 January 2014). 